\title{
Antibodies to early pregnancy factor retard embryonic development in mice in vivo
}

\author{
S. Athanasas-Platsis ${ }^{1}$, H. Morton ${ }^{1}$, G. F. Dunglison ${ }^{2}$ and P. L. Kaye ${ }^{2}$ \\ 'University of Queensland, Department of Surgery, Clinical Sciences Building, Royal Brisbane \\ Hospital, QId 4029, Australia and ${ }^{2}$ University of Queensland, Department of Physiology and \\ Pharmacology, Qld 4072, Australia
}

\begin{abstract}
Summary. Previous work in this laboratory has shown that passive immunization of mice against early pregnancy factor (EPF) leads to failure to maintain pregnancy. The findings presented in this paper demonstrate that this treatment affects the development of the embryos very early in gestation. By Day 3,54 and $25 \%$ of embryos in the 2 groups treated with anti-EPF immunoglobulin $(\mathrm{Ig}) \mathrm{G}$ and $\operatorname{IgM}$, respectively, had not developed to the 4-cell stage, compared with 12 and $1 \%$ in the control groups. None of the embryos in the mice treated with anti-EPF had developed beyond the 8-cell stage. A similar delay in development after treatment was observed on Day 4. The effect apparent during the early stages of cleavage is an indirect rather than a direct one, as 2 -cell embryos $(32-36 \mathrm{~h}$ post coitum), cultured in vitro in the presence of anti-EPF antibodies, developed uninterrupted to the morula and blastocyst stage. The delay in development did not appear to be caused by a disruption of the normal pattern of circulating progesterone, as progesterone concentrations on Day 4 were within the normal range for Quackenbush mice.
\end{abstract}

\begin{abstract}
Keywords: early pregnancy factor; pregnancy; monoclonal antibodies; embryonic development; passive immunization; mouse
\end{abstract}

\section{Introduction}

Early pregnancy factor (EPF), released from the ovary in response to the presence of a viable embryo, is necessary for the maintenance of a successful pregnancy. This has been demonstrated in mice in which passive immunization against EPF either at 32 and $56 \mathrm{~h}$ post coitum (p.c.) with anti-EPF monoclonal immunoglobulin (Ig)M or at $8,16,32$ and $40 \mathrm{~h}$ p.c. with anti-EPF polyclonal $\mathrm{IgG}$ resulted in a significant reduction in the number maintaining their pregnancies to Day 10 (Athanasas-Platsis et al., 1989).

Two roles have been suggested for EPF in maintenance of embryonic viability. The first is that of immunosuppression. EPF induces the production of suppressor factors from lymphocytes which, in turn, can suppress certain immunological responses such as the delayed-type hypersensitivity reaction (Rolfe et al., 1988). It has been postulated that these suppressor factors may play a role in the prevention of maternal reactions against the developing embryo. The second role is that of a growth factor. Recent studies in our laboratory have shown that, as well as being produced by embryonic cells after implantation, EPF is produced by actively dividing tumour cells and that these cells require EPF for their growth and viability; monoclonal antibodies to EPF perturb tumour cell growth both in vivo and in vitro (Quinn et al., 1990).

In the light of the above findings, further investigations have been carried out to define more precisely the role(s) of EPF in pregnancy. To determine whether the loss of viability noted at Day 10 of pregnancy was due to (i) normal development with failure to implant, (ii) retarded development with subsequent failure to implant or (iii) death of the embryo before implantation, mated 
mice were injected with monoclonal and polyclonal antibodies to EPF on Days 1 and 2 of pregnancy; oviducts and uterine horns were flushed on Days 3 or 4 and the stage of development of the fertilized eggs was recorded. To determine whether the antibodies have a direct effect on embryonic development, 2-cell stage embryos were cultured in vitro, away from the pre-implantation source of EPF, the ovary, or other maternal influences, in the presence or absence of anti-EPF antibodies, and the stage of development was recorded.

\section{Materials and Methods}

\section{Mating protocol}

Mature, virgin outbred Quackenbush mice (Central Animal Breeding House, Brisbane, Australia) were housed in a light ( $12 \mathrm{~h} \mathrm{light,} 12 \mathrm{~h}$ dark) and temperature-controlled $\left(22.26^{\circ} \mathrm{C}\right)$ room, with free access to water and mouse pellets. Female mice were caged overnight with males $(1: 1)$ and mating was confirmed the next morning by the appearance of a vaginal plug; $0 \mathrm{~h}$ was taken as $02: 00 \mathrm{~h}$ on the day of mating (Day 1). Where indicated, female mice were superovulated by i.p. injection of $10 \mathrm{iu}$ each of pregnant mares' serum gonadotrophin (PMSG) and human chorionic gonadotrophin (hCG) given $48 \mathrm{~h}$ apart; ovulation occurred 12-16 h later (Edwards \& Gates, 1959).

\section{Monoclonal antibodies}

Production. Anti-EPF (5/341) and control (7/331) monoclonal antibodies were produced and characterized as IgM by methods described by Athanasas-Platsis el al. (1989).

Purification. Hybridoma supernatant containing either anti-EPF or control (not of anti-EPF specificity) IgM was diluted 1 in 10 with distilled water and $\mathrm{pH}$ adjusted to 8.0 with $\mathrm{IN}-\mathrm{NaOH}$. Chromatography was performed on a Zeta Prep ${ }^{\circledR}$ QAE cartridge (Cuno Pacific, Blacktown, NSW, Australia) using $10 \mathrm{~mm}$ Tris pH 8.0 buffer $/ 0.01 \%$ (w/v) sodium azide as equilibrating and washing buffer and $50 \mathrm{~mm}$ sodium phosphate $\mathrm{pH} 7.4$ buffer $/ 1 \mathrm{M}-\mathrm{NaCl} / 0.01 \%$ sodium azide as elution buffer, according to the manufacturer's instructions. The pooled eluate was treated to remove EPF (see Athanasas-Platsis et al., 1989) by acidification to $\mathrm{pH} 2.5$ with $0.2 \mathrm{M}$ glycine- $\mathrm{HCl}, \mathrm{pH} 2.0$ (to separate antigen-antibody complexes), mixed at $4^{\circ} \mathrm{C}$ for $0.5 \mathrm{~h}$ and passed through an activated $\mathrm{C}_{18}$ Sep-pak (Waters Assoc., Milford, MA, USA) which binds EPF. The flow-through fraction containing IgM was collected, the $\mathrm{pH}$ raised to 60 with solid Tris and precipitated against $1 \mathrm{~mm}$ sodium phosphate buffer, $\mathrm{pH} 6.0$, washed twice with this buffer and resuspended in phosphate-buffered saline and $0.01 \%$ sodium azide. Purity of the final preparation was confirmed by sodium dodecyl sulphate polyacrylamide gel electrophoresis (SDS-PAGE) (Gorg et al., 1981) and protein concentration determined (Lowry et al., 1951).

\section{Polyclonal antibodies}

Production. Rabbit anti-EPF $\$ 816$ and normal rabbit control polyclonal antibodies were produced and characterized as IgG by methods described by Athanasas-Platsis et al. (1989).

Purification. IgG was isolated from rabbit serum by precipitation with $45 \%$ ammonium sulphate, followed by chromatography on a Zeta Prep ${ }^{\circledR}$ DEAE cartridge (Cuno Pacific) using $20 \mathrm{~mm}$ sodium phosphate buffer, $\mathrm{pH} 6.3 / 50 \mathrm{~mm}-\mathrm{NaCl} / 0.01 \%$ sodium azide as equilibrating and elution buffer, according to the manufacturer's instructions. Purity of the final preparation was confirmed by SDS-PAGE (Gorg et al., 1981) and protein concentration determined (Lowry et al., 1951).

\section{Screening of anti-EPF IgG and IgM for embryotoxicity}

Freshly collected compacted morulae and blastocysts were cultured overnight in BMOC-2 culture medium (Brinster, 1965 as modified by Pemble \& Kaye, 1986) with or without anti-EPF monoclonal IgM 5/341, anti-EPF polyclonal IgG $\$ 816$ or control polyclonal IgG, at dilutions ranging from 500 to $2.5 \mu \mathrm{g} / \mathrm{ml}$. Before culture with embryos, antibody preparations were exchanged into BMOC-2 culture medium on a PD-10 column (Sephadex G25M, Pharmacia, Uppsala, Sweden) followed by dilutions with BMOC-2 medium. Next morning, guinea-pig complement ( $1: 20$ dilution; CSL Melbourne, Australia) was added, and embryos were examined $24 \mathrm{~h}$ later.

\section{Effect of anti-EPF antibodies on pre-implantation embryonic development in vivo}

Passive immunization. Groups of confirmed-mated female mice were injected i.p. with $500 \mu \mathrm{g}$ of either anti-EPF monoclonal IgM $5 / 341$ or polyclonal IgG $\$ 816$ at $8,16,32$ and $40 \mathrm{~h}$ p.c. This dose of anti-EPF antibody, given at 
these times, blocks pregnancy in a significant number of cases (Athanasas-Platsis et al., 1989). Control groups received injections of $500 \mu \mathrm{g}$ control monoclonal IgM 7/331, control polyclonal IgG or $0.9 \% \mathrm{NaCl}$ (saline) at $8,16,32$ and $40 \mathrm{~h}$ p.c. Before injection, antibody preparations were dialysed overnight against saline. On Days 3 or 4 (between 09:00 and 12:00 h) of pregnancy, mice were bled, serum was collected, the number of corpora lutea counted and the oviducts and uterine horns flushed with saline, to recover embryos. The number and stage of development of embryos were recorded. The mice killed on Day 4 of pregnancy were first injected with $100 \mu 11 \%(w / v)$ Pontamine Sky Blue in saline into the tail vein. At autopsy 15 min later, the number of dye sites, if any, were counted.

\section{In-vitro experiments}

Embryo culture. Two-cell embryos ( $48 \mathrm{~h}$ after hCG, i.e. $32-36 \mathrm{~h}$ p.c.) were collected from superovulated mice and washed extensively in M2 medium (Fulton \& Whittingham, 1978) modified to contain $0.33 \mathrm{~mm}$ sodium pyruvate (Sigma Chemical Co., St Louis, Mo, USA), $5.6 \mathrm{~mm}$ glucose and $4 \mathrm{~g}$ bovine serum albumin (BSA; Sigma Product No. A-9647)/l. Before culture with embryos, antibody preparations were exchanged into BMOC-2 culture medium. Embryos were cultured in $20-\mu$ l droplets of BMOC-2 medium containing the various concentrations of anti-EPF monoclonal $\operatorname{IgM} 5 / 341$, anti-EPF polyclonal IgG $\$ 816$, control polyclonal IgG or culture medium alone under liquid paraffin oil (BDH Chemicals Ltd, UK) in a humidified atmosphere of $5 \% \mathrm{CO}_{2}, 5 \% \mathrm{O}_{2}$ and $90 \% \mathrm{~N}_{2}$ at $37^{\circ} \mathrm{C}$ for $48 \mathrm{~h}$. After this, the stage of development and morphology of embryos were recorded.

Protein synthesis in embryos. After $48 \mathrm{~h}$ in culture, blastocysts and morulae were transferred to droplets of the same medium containing $6 \mu \mathrm{M}\left[4,5-{ }^{3} \mathrm{H}\right]$ leucine (Amersham International, Amersham, UK; $1 \mathrm{Ci} / 1$ ) and incubated for $2 \mathrm{~h}$ before determining the rate of protein synthesis (Harvey \& Kaye, 1988).

\section{Progesterone assay}

The progesterone concentration in serum was measured by radioimmunoassay using an antiserum to progesterone (prepared by Dr R. I. Cox, Division of Animal Production, CSIRO, Prospect, NSW, Australia). Two serum pools, containing high and low concentrations of progesterone, respectively, were included in the assay in order to calculate the intra-assay coefficients of variation. Parallelism was demonstrated using graded dilutions $(1 / 20$ to $1 / 1)$ of a serum sample containing $\sim 10 \mathrm{ng}$ progesterone/ml.

For assay, $50-\mu \mathrm{l}$ serum samples were diluted to $250 \mu \mathrm{l}$ with $600 \mathrm{~mm}$ sodium phosphate buffer, $\mathrm{pH} 7 \cdot 2 / 0.01 \%(\mathrm{w} / \mathrm{v})$ gelatin (gelatin buffer) and $50-\mu l$ aliquants in triplicate were extracted in $3 \mathrm{ml}$ of freshly redistilled hexane (May and Baker Australia Pty, Ltd) and dried under nitrogen (extraction efficiency $89.2 \%$ ). Extracts were resuspended in $100 \mu$ l gelatin buffer. Standards were prepared from progesterone (Sigma) in gelatin buffer at various concentrations (0 $2048 \mathrm{pg} /$ tube). Extracts and standards were then allowed to stand at room temperature for $3 \mathrm{~h}$ prior to the addition of $100 \mu \mathrm{l}$ antiserum $\left(\mathrm{l} / 10000\right.$ in gelatin buffer) and $100 \mu \mathrm{l}\left[1 \alpha, 2 \alpha(\mathrm{n})-{ }^{3} \mathrm{H}\right]$ progesterone $(10000$ c.p.m., $2.04 \mathrm{TBq} / \mathrm{mmol}$; Amersham) in gelatin buffer. Tubes were incubated overnight at $4^{\circ} \mathrm{C}$, followed by separation of bound and free steroid with $300 \mu \mathrm{l} 0.625 \%$ charcoal $/ 0.0625 \%$ dextran in gelatin buffer for $10 \mathrm{~min}$ at $4 \%$. Following centrifugation, the supernatant was removed, added to $3 \mathrm{ml}$ scintillation fluid (toluene, containing $0.3 \% 2$, 5-diphenyloxazole, $0.03 \%$ 1, 4-di-[2-(5-phenyl-oxazolyl)]-benzene and 5\% acetic acid) and radioactivity was measured in an LKB scintillation counter. A standard curve was calculated according to a logit transformation and progesterone concentrations in unknown serum samples were determined from this curve and expressed as ng progesterone/ml serum. The sensitivity of the assay (calculated as two standard deviations from the blanks) was $<16 \mathrm{pg} /$ tube. The intra-assay coefficients of variation were 8.4 and $7.6 \%$ for high and low serum pools, respectively.

\section{Statistical analysis}

Differences between the number of embryos at the various stages of development for treatment and control groups were determined by the $\chi^{2}$ test. Differences between mean protein synthesis rate in embryos for treatment and control groups were determined by analysis of variance (ANOVA). Differences between mean progesterone values for treatment and control groups were determined by Student's $t$ test. Differences were considered significant when a $P$ value of $<0.05$ was obtained.

\section{Results}

\section{Effect of anti-EPF antibodies on in-vivo development of the embryo}

Treatment with polyclonal anti-EPF IgG $\$ 816$ resulted in only 33 of $71(46 \%)$ embryos developing to the 48 -cell stage by Day 3 of pregnancy, while the remaining embryos $(54 \%)$ were retarded and had not reached the 4-cell stage; $45 \%$ of these retarded embryos had not developed beyond the fertilized egg stage (Fig. 1). In contrast, treatment with normal rabbit polyclonal IgG 
resulted in 73 of $106(69 \%)$ embryos developing to the 4-8-cell stage and only $12 \%$ of embryos did not develop to the 4-cell stage by this time $\left(P<0.001, \chi^{2}\right.$ test) (Fig. 1). Results obtained with monoclonal anti-EPF IgM 5/34I were not as impressive, but a significant treatment effect was demonstrated when results were compared with those obtained with control $\operatorname{IgM} 7 / 331$. At the $<4$-cell stage, a significant difference was observed; $25 \%$ of embryos treated with anti-EPF IgM $5 / 341$ were retarded compared with $1 \%$ of embryos treated with control $\operatorname{IgM}\left(P<0.001, \chi^{2}\right.$ test $)$. None of the embryos treated with polyclonal anti-EPF IgG or monoclonal anti-EPF IgM had developed beyond the 8 -cell stage by Day 3 (Fig. 1).

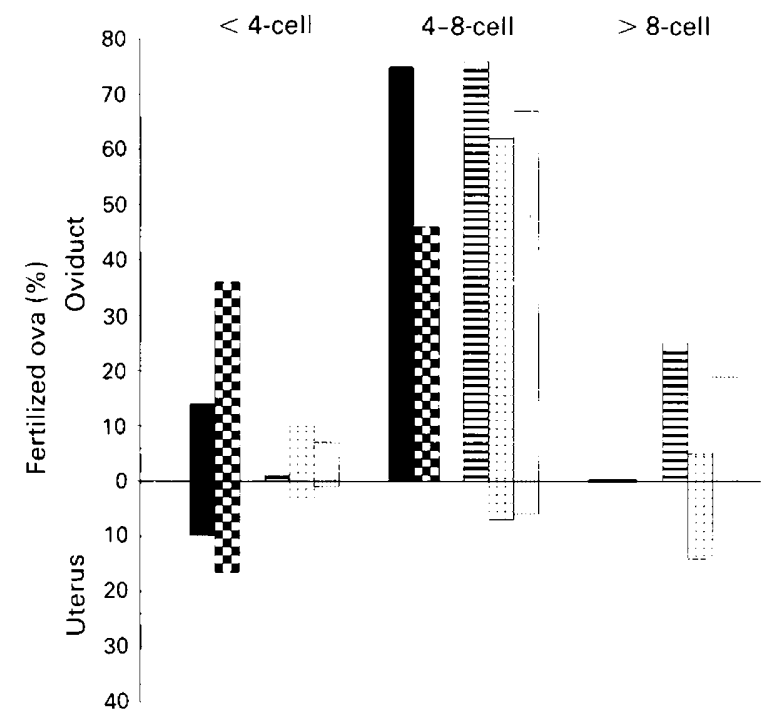

Fig. 1 Stage of development of embryos recovered from the oviduct or uterus on Day 3 of pregnancy after passive immunization of mated mice on Days 1 and 2 with $500 \mu \mathrm{g}$ anti-EPF monoclonal immunoglobulin (Ig) M 5/341 ( $\square, n=77)$, anti-EPF polyclonal IgG $\$ 816$

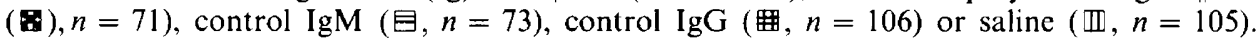
Values in parentheses are the total number of embryos recovered/treatment group. Anti-EPF $\operatorname{IgM}$ vs. control $\operatorname{IgM}\left(P<0.001, \chi^{2}\right.$ test $)$, anti-EPF $\operatorname{IgG}$ vs. control $\operatorname{IgG}\left(P<0.001, \chi^{2}\right.$ test $)$.

To determine whether development in retarded embryos accelerated prior to implantation, the experiments were repeated, but oviducts and uterine horns were flushed on Day 4 of pregnancy. Treatment of embryos with polyclonal anti-EPF IgG $\$ 816$ resulted in 52 of $97(54 \%)$ embryos developing to the expected morula/blastocyst stage whereas 45 of $97(46 \%)$ did not develop beyond the 16-cell stage (Fig. 2); $42 \%$ of these retarded embryos did not develop beyond the fertilized egg stage. When comparing these results with those obtained after control IgG treatment, an obvious treatment effect was observed $\left(P<0.001, \chi^{2}\right.$ test $)$. Treatment with anti-EPF monoclonal IgM $5 / 341$ resulted in 59 of $74(80 \%)$ embryos developing to the morula/blastocyst stage, with $20 \%$ retarded ( $<16$ cell stage) (Fig. 2). When comparing these results with those of the control IgM $7 / 331$, a significant treatment effect was again observed $\left(P<0.001, \chi^{2}\right.$ test $)$. A similar percentage of embryos was retarded on Day $4(20 \%)$ as on Day $3(25 \%)$. At autopsy on Day 4 p.c., no implantation sites were detected by the Pontamine Blue reaction in mice injected with either antibody or saline.

\section{Effect of anti-EPF antibodies on tubal transport of embryos}

On Day 3 of a normal murine pregnancy, embryos at the 4-8-cell stage are predominantly found in the oviduct. The majority of embryos in the treatment and control groups were found in 


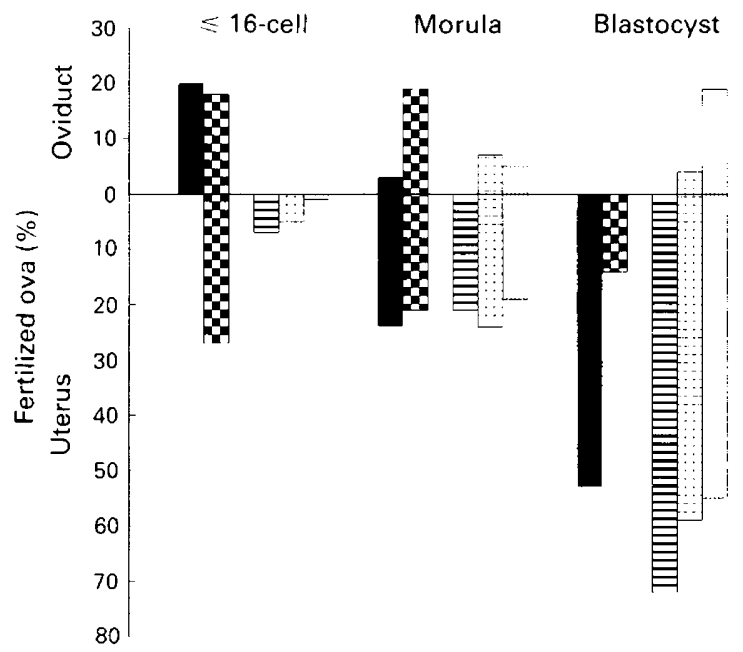

Fig. 2. Stage of development of embryos recovered from the oviduct or uterus on Day 4 of pregnancy after passive immunization of mated mice on Days 1 and 2 with $500 \mu \mathrm{g}$ anti-EPF monoclonal immunoglobulin (Ig) M 5/341 (,$n=74)$, anti-EPF polyclonal IgG $\$ 816$ ( $\mathbf{Q}, n=97)$, control IgM (目, $n=75$ ), control IgG (聿, $n=89$ ) or saline ( $\mathbb{L}, n=78$ ). Values in parentheses are the total number of embryos recovered/treatment group. Anti-EPF IgM vs. control $\operatorname{IgM}\left(P<0.001, \chi^{2}\right.$ test $)$, anti-EPF IgG vs. control $\operatorname{IgG}\left(P<0.001, \chi^{2}\right.$ test $)$.

the oviduct, although accelerated transport of some retarded embryos was observed after anti-EPF polyclonal and monoclonal antibody treatment (Fig. 1). In the group treated with anti-EPF polyclonal IgG $\$ 816,12$ of $71(17 \%)$ embryos, which were at a stage $<4$ cells, were found in the uterus compared with 3 of $106(3 \%)$ embryos in the control group $\left(P<0.01, \chi^{2}\right.$ test). Treatment with anti-EPF monoclonal IgM 5/341 accelerated tubal transport in 8 of $77(10 \%)$ embryos at $<4$-cell stage whereas no accelerated transport was demonstrated with control $\operatorname{IgM} 7 / 331\left(P<0.02, \chi^{2}\right.$ test).

\section{Effect of anti-EPF antibodies on in-vitro development and rate of protein synthesis in embryos}

Treatment of 2-cell embryos in culture with different concentrations of control IgG, anti-EPF polyclonal IgG or anti-EPF monoclonal IgM did not affect the rate of embryonic development. Approximately $80 \%$ of 2 -cell embryos treated with anti-EPF antibodies and control antibody developed to the morula/blastocyst stage after $48 \mathrm{~h}$. There was no significant difference in rate of protein synthesis between blastocysts or late morulae from treatment and control cultures at all concentrations of antibody (Table 1). The addition of complement to treatment and control cultures of morulae and blastocysts did not affect viability or development.

\section{Serum progesterone concentration after anti-EPF antibody treatment}

Since progesterone concentration begins to rise at about Day 3 of pregnancy in mice (Finn \& Martin, 1969), serum progesterone concentration was only measured on Day 4 . The concentration of progesterone was unaffected after anti-EPF treatment (Table 2); there was no significant difference between concentrations in mice treated with anti-EPF polyclonal IgG and control IgG, nor between mice treated with anti-EPF monoclonal IgM and control IgM. The concentrations obtained in all groups were within the normal range expected on Day 4 of pregnancy (McCormack $\&$ Greenwald, 1974) for this particular strain of mouse. The average number of corpora lutea was similar in all groups on Days 3 (data not shown) and 4 of pregnancy (Table 2). 
Table 1. Protein synthesis assessed by $\left[4,5-{ }^{3} \mathrm{H}\right]$ leucine incorporation by mouse embryos after $48 \mathrm{~h}$ in culture with anti-EPF polyclonal rabbit immunoglobulin (lg) $\mathrm{G} \$ 816$, anti-EPF monoclonal mouse IgM 5/341 or control rabbit IgG

\begin{tabular}{|c|c|c|c|c|c|}
\hline \multirow[b]{2}{*}{$\begin{array}{l}\text { Embryo } \\
\text { stage }\end{array}$} & \multirow[b]{2}{*}{$\begin{array}{l}\text { Conc. of } \\
\text { antibody } \\
(\mu \mathrm{g} / \mathrm{ml})\end{array}$} & \multicolumn{4}{|c|}{$\begin{array}{c}{\left[4,5-{ }^{3} \mathrm{H}\right] \text { leucine incorporation }} \\
\text { (c.p.m./embryo } / 2 \mathrm{~h} \text { ) }\end{array}$} \\
\hline & & $\begin{array}{l}\text { Medium } \\
\text { alone }\end{array}$ & $\begin{array}{l}\text { Control } \\
\text { rabbit } \\
\text { IgG }\end{array}$ & $\begin{array}{c}\text { Anti-EPF } \\
\text { polyclonal } \\
\text { rabbit IgG } \\
\$ 816\end{array}$ & $\begin{array}{c}\text { Anti-EPF } \\
\text { monoclonal } \\
\text { mouse IgM } \\
5 / 341\end{array}$ \\
\hline \multirow[t]{5}{*}{ Late morula } & 0 & $11519 \pm 1349$ & - & - & - \\
\hline & $2 \cdot 5$ & - & $15608 \pm 2747$ & $13133 \pm 905$ & $12292 \pm 2473$ \\
\hline & 25 & - & $12899 \pm 957$ & $10650 \pm 2022$ & $13914 \pm 2151$ \\
\hline & 250 & - & $12397 \pm 2529$ & $8004 \pm 2553$ & $9130 \pm 1245$ \\
\hline & 500 & - & $9908 \pm 853$ & $8170 \pm 1769$ & $14206 \pm 1604$ \\
\hline \multirow[t]{5}{*}{ Blastocyst } & 0 & $22869 \pm 1495$ & - & $=$ & - \\
\hline & $2 \cdot 5$ & - & $21206 \pm 2352$ & $24290 \pm 1309$ & - \\
\hline & 25 & - & $22847 \pm 1489$ & $19559 \pm 1229$ & $24290 \pm 3041$ \\
\hline & 250 & - & $21184 \pm 1265$ & $20260 \pm 1203$ & $20320 \pm 1587$ \\
\hline & 500 & - & $19716 \pm 1282$ & $18247 \pm 1252$ & $17442 \pm 1681$ \\
\hline
\end{tabular}

Data are from 3 experiments each containing a minimum of 4 embryos/treatment and are means \pm s.e.m.

Table 2. Effect of passive immunization at Day 1 and Day 2 post coitum with anti-EPF polyclonal rabbit IgG $\$ 816$ and anti-EPF monoclonal mouse IgM $5 / 341$ on the number of corpora lutea and serum progesterone concentration at Day 4 post coitum

\begin{tabular}{llccc}
\hline \multicolumn{1}{c}{ Treatment } & $\begin{array}{c}\text { No. of } \\
\text { animals } \\
\text { treated }\end{array}$ & $\begin{array}{c}\text { No. of corpora } \\
\text { lutea/ovary }\end{array}$ & $\begin{array}{c}\text { Serum } \\
\text { progesterone } \\
(\mu \mathrm{g} / \mathrm{ml})\end{array}$ \\
\hline Day 4 & $\begin{array}{l}\text { Anti-EPF polyclonal IgG } \\
\$ 816\end{array}$ & 6 & $7.5 \pm 0.36$ & $25.9 \pm 3.9^{*}$ \\
& & 6 & $6.43 \pm 0.36$ & $40.3 \pm 4.3^{*}$ \\
& $\begin{array}{l}\text { Anti-EPF monoclonal IgM } \\
\text { 5/341 }\end{array}$ & 6 & $6.75 \pm 0.37$ & $31.9 \pm 3.9$ \\
$\begin{array}{l}\text { Control polyclonal IgG } \\
\text { Control monoclonal IgM }\end{array}$ & 6 & $6.67 \pm 0.28$ & $37.6 \pm 2.2$ \\
$\begin{array}{l}7 / 331 \\
\text { Saline }\end{array}$ & 6 & $6.58 \pm 0.31$ & $28.1 \pm 4.7$ \\
\hline
\end{tabular}

*Not significant (Student's $t$ test) when compared with control IgG and saline.

Data are means \pm s.e.m.

\section{Discussion}

Previous work in this laboratory has shown that passive immunization of mice against EPF leads to failure to maintain pregnancy (Athanasas-Platsis et al., 1989). It has not been determined at which stage of gestation anti-EPF treatment affects development. The findings presented in this paper demonstrate that this treatment affects the development of embryos very early in gestation, at around the 1-2-cell stage, leading to retardation in embryonic development with subsequent failure to implant. The effect observed after passive immunization of pregnant mice with anti-EPF antibodies is different from that observed after passive immunization with anti-progesterone antibodies. In the latter case, Rider et al. (1987) found that the establishment of pregnancy in mice is 
affected by passive immunization against progesterone at around the 4-cell stage of development and at the peri-implantation stage. Our studies have revealed that the development of the embryo is susceptible to passive immunization against EPF before the 4-cell stage. Failure of pregnancy to continue after anti-EPF treatment seems to result from asynchronization between the development of the embryo and the uterus, rather than from a direct effect on implantation. Embryos which develop too slowly miss the short period of uterine receptivity during which implantation occurs (McLaren \& Bowman, 1973).

The effect, apparent during the early stages of cleavage, is an indirect rather than a direct one, as morphological development proceeded uninterrupted to the blastocyst stage when 2-cell embryos were cultured in vitro in the presence of anti-EPF antibodies. Moreover, measurements of rate of protein synthesis, which is a very sensitive assay of physiological state, showed no effect of antiEPF antibodies. Studies by Quinn et al. (1990) have shown that, in the growth of tumour cells, EPF has a role as an autocrine growth factor. The normal development of the embryos in vitro in the presence of anti-EPF antibodies and the fact that the pre-implantation embryo does not produce EPF (Morton et al., 1987) negates this role for EPF in the survival of the pre-implantation embryo. EPF may be acting indirectly at this stage, by initiating systems in vivo which are important to embryo survival.

This leads us to another role suggested for EPF, that of immunosuppression. EPF induces the production, from lymphocytes, of suppressor factors (Rolfe et al., 1988) which may alter some maternal reaction to the fertilized ova. The nature of this maternal reaction needs further investigation, but evidence provided by Hill et al. (1987) may have thrown some light on the subject: they cultured 2-cell mouse embryos with supernatants from activated human and mouse leucocyte cultures and with recombinant lymphokines and monokines and reported arrested embryonic development at the 2-cell to morula stages. Lymphokines such as IFN- $\alpha$, colony-stimulating factor (CSF) and B cell growth factor inhibited embryonic development. Interleukin-2 (IL-2) had no effect on embryonic development, although Tezabwala et al. (1989) reported inhibition of pregnancy in mice injected on Day 1 with murine and human IL-2. Of the monokines tested, recombinant tumour necrosis factor (r-TNF) and recombinant interleukin-I inhibited development. Furthermore, Tartakovsky (1989/1990) reported induced resorption of embryos in mice after 5 daily injections of CSF-1-conditioned medium. When taken together, these results suggest that, during pregnancy, mechanisms exist which reduce the expression of all or some lymphokines (Nicholas et al., 1984; Bulmer \& Johnson, 1986) and monokines. If these mechanisms are disrupted, maternal cellular cytotoxic responses come into play. EPF, or rather its suppressor factors, may suppress these maternal responses so that the embryo may enjoy unperturbed growth and development.

Passive immunization acts through the high-affinity binding of antigens, preventing their interaction with target cell receptors (Rider et al., 1987). Preliminary studies have shown that mice which were positive for EPF (see Morton et al., 1987; Athanasas-Platsis et al., 1989) at 10:00 h p.c., prior to the first two doses of anti-EPF antibodies at 8 and 16 h p.c., displayed either reduced EPF titres or had no detectable EPF in serum collected at $24 \mathrm{~h}$ p.c. (unpublished observations). It is possible that this neutralization of EPF in vivo prevents its induction of suppressor-factor release from lymphocytes; this, in turn, may allow expression of maternal cellular cytotoxic responses. This postulate needs further investigation, but the production of monoclonal antibodies to the EPF-induced suppressor factors and the administration of these to pregnant mice in experiments similar to those described in this paper will help to determine whether these suppressor factors play a role in pregnancy.

In addition, EPF may be a necessary component in the complex network of hormonal events leading to successful development and implantation of the embryo. The possibility that neutralization of EPF may disrupt the normal pattern of circulating progesterone has been dispelled, as progesterone concentrations on Day 4 (after anti-EPF treatment) were within the normal range for Quackenbush mice. It is generally accepted that ovarian hormones play an important role in the 
regulation of ovum transport (Forcelledo et al., 1981) and that oestrogen, depending on the species of animal, the dose (Greenwald, 1967) and the time of administration (Humphrey, 1968), can cause accelerated or delayed tubal transport.

In our studies, transport of ova was accelerated in some mice, but not in others, after anti-EPF treatment. If neutralization of EPF disrupts oestrogen concentrations, the above could reflect increased susceptibility of some mice to changes in hormone concentrations. Furthermore, Roblero et al. (1983) reported reduced cleavage rate and arrested embryonic development after post-coital administration of different doses of oestrogen. Further investigations on the effect of neutralization of EPF on oestrogen concentrations need to be conducted before any assertive statements can be made. Nevertheless, from the results presented in this paper, it can be concluded that, in vivo, EPF is required for embryonic development very early in gestation. Whether EPF alters an immune response, a hormonal response or both requires further investigation.

We thank Mr J. Kennedy for performing the progesterone assay, Dr G. Pollock for graphics and Mrs S. Davy and Mrs J. Corcoran for typing the manuscript. This work was supported by funding from the National Health and Medical Research Council.

\section{References}

Athanasas-Platsis, S., Quinn, K.A., Wong, T-Y., Rolfe, B.E., Cavanagh, A.C. \& Morton, H. (1989) Passive immunization of pregnant mice against early pregnancy factor causes loss of embryonic viability. $J$. Reprod. Fert. 87, 495-502.

Brinster, R.L. (1965) Studies on the development of mouse embryos in vitro. IV. Interaction of energy sources. J. Reprod. Fert. 10, 227-240.

Bulmer, J.N. \& Johnson, P.M. (1986) The lymphocyte population in first trimester human decidua does not express the interleukin-2 receptor. Immunology 58, $685-687$.

Edwards, R.G. \& Gates, A.H. (1959) Timing of the stages of maturation divisions, ovulation, fertilization and the first cleavage of adult mice treated with gonadotrophins. J. Endocr. 18, 292-304.

Finn, C.A. \& Martin, L. (1969) Hormone secretion during early pregnancy in the mouse. $J$. Endocr. 45, $57-65$.

Forcelledo, M.L., Vera, R. \& Croxatto, H. B. (1981) Ovum transport in pregnant, pseudopregnant and cyclic rats and its relationship to estradiol and progesterone blood levels. Biol. Reprod. 24, 760-765.

Fulton, B. \& Whittingham, D. (1978) Activation of mammalian oocytes by intracellular injection of calcium. Nature, Lond. 273, 149-151.

Gorg, A., Postel, W., Westermeier, R., Gianazza, E. \& Righetti, P.G. (1981) SDS-gel gradient electrophoresis, isoelectric-focusing and high-resolution two dimensional electrophoresis. In Electrophoresis '81, pp. 259-270. Eds R. C. Allen \& P. Arnaud. Walter de Gruyter Publishers, Berlin.

Greenwald, G.S. (1967) Species differences in egg transport in response to exogenous estrogen. Anat. Rec. 157, $163-172$.

Harvey, M.B. \& Kaye, P.L. (1988) Insulin stimulates protein synthesis in compacted mouse embryos. Endocrinology 122, $1182 \cdots 1184$.

Hill, J.A., Haimovici, F. \& Anderson, D.J. (1987) Products of activated lymphocytes and macrophages inhibit mouse embryo development in vitro. J. Immunol. 139, $2250-2254$.

Humphrey, K.W. (1968) The effects of oestradiol-3-17 $\beta$ on tubal transport in the laboratory mouse. $J$. Endocr, 42, 17-26.

Lowry, O.H., Rosebrough, N.J., Farr, A.L. \& Randall, R.J. (1951) Protein measurement with the folin phenol reagent. J. biol. Chem. 193, 265-275.

McCormack, J.T. \& Greenwald, G.S. (1974) Progesterone and oestradiol-17 $\beta$ concentrations in the peripheral plasma during pregnancy in the mouse. $J$. Endocr. 62, $101-107$.

McLaren, A. \& Bowman, P. (1973) Genetic effects on the timing of early development in the mouse. J. Embryol. exp. Morph. 30, 491-498.

Morton, H., Rolfe, B.E. \& Cavanagh, A.C. (1987) Ovum factor and early pregnancy factor. In Current Topics in Developmental Biology Vol.23, pp. 73-92. Eds A. McLaren \& G. Siracusa. Academic Press, San Diego.

Nicholas, N.S., Panayi, G.S. \& Nouri, A.M.E. (1984) Human pregnancy serum inhibits IL-2 production. Clin. exp. Immunol. 58, 587-595.

Pemble, L.B. \& Kaye, P.L. (1986) Whole protein uptake and metabolism by mouse blastocysts. J. Reprod. Fert. 78, $149-157$.

Quinn, K.A., Athanasas-Platsis, S., Wong, T-Y., Rolfe, B.E., Cavanagh, A.C. \& Morton, H. (1990) Monoclonal antibodies to early pregnancy factor perturb tumor cell growth. Clin. exp. Immunol. 80, 100-108.

Rider, V., Heap, R.B., Wang, M-Y. \& Feinstein, A. (1987) Anti-progesterone monoclonal antibodies affect early cleavage and implantation in the mouse by mechanisms that are influenced by genotype. J. Reprod. Fert. 79, 33-43.

Roblero, L., Moscoso, H. \& Riffo, M. (1983) Effects of oestradiol upon transport, growth, differentiation and viability of preimplantation mouse embryos. Archs. Biol. Med. Exp. 16, 55-59. 
Rolfe, B.E., Cavanagh, A.C., Quinn, K.A. \& Morton, H. Tezabwala, B.U., Johnson, P.M. \& Rees, R.C. (1989) (1988) Identification of two suppressor factors induced by early pregnancy factor. Clin. exp. Immunol. 73, 219-225.

Tartakovsky, B. (1989/1990) CSF-I induces resorption of embryos in mice. Immunol. Lett. 23, 65-70.

Inhibition of pregnancy viability in mice following

IL-2 administration. Immunology 67, 115-119.

Received 10 September 1990 